\title{
HYPERSENSITIVITY TO COLCHICINE
}

\author{
BY \\ J. G. MACLEOD and L. PHILLIPS \\ From the Departments of Medicine and Pathology, Edinburgh University
}

A patient suffering from atypical arthritis of the rheumatoid type was given crystalline colchicine in the usual dose as a diagnostic measure because the possibility of gout had been suggested by the radiological and biochemical findings. Death from colchicine poisoning resulted. In the present paper an attempt is made to assess the significance of this, and of other unusual features of the case.

\section{Case History}

A married man, aged 39, gave a twelve years' history of pain and swelling of various joints. These symptoms commenced in fingers and feet in 1934, and in later years the right wrist, knees, hips, neck, and jaws were affected. Since 1941 glandular swellings had been noted in groins and axillae whenever symptoms were severe. These swellings disappeared with improvement in the joints. In January, 1946, all teeth were extracted, and thereafter the left wrist also became swollen and painful. In the first five years of his illness the patient lost weight and was unduly tired, but latterly his weight had been steady. He had no other symptoms apart from epigastric pain two hours after food, readily controlled by dietetic measures. A duodenal ulcer had been diagnosed radiologically.

The only previous illnesses were influenza, pleurisy, and lumbago in 1930 . The patient was temperate in his habits. Acute exacerbations of pain were not related to over-indulgence in food or drink. There was no family history of arthritis or gout.

On several occasions courses of gold had been prescribed without benefit. The most recent course had to be stopped after $0.6 \mathrm{~g}$. of myocrysin because of an exacerbation of symptoms in the left wrist. Other treatment, such as paraffin wax baths, " electrical treatment ", and tonsillectomy had not helped him. Although for twelve years the patient had always symptoms in one or more joints he was usually able to continue at work as an upholsterer.

When first seen as an out patient in November, 1946, the patient was a sparely built man with a good colour. There was a moderate degree of swelling and limitation of movement at both wrist joints and at the right ankle. Similar but less marked changes were present in the left first and second metacarpo-phalangeal and proximal interphalangeal joints. No enlargement of lymph glands was detected at this time, and examination of all other systems was negative.

The blood sedimentation rate was $22 \mathrm{~mm}$. in one hour (Westergren), and the blood uric acid was $4.4 \mathrm{mg}$. per $100 \mathrm{c.cm}$. of blood. Skiagrams showed destructive changes in the right wrist and in the left thumb and index finger, and soft-tissue swelling of the wrists. Punched-out areas, present in the left index finger and thumb, were suggestive of gout, but the other appearances were those of rheumatoid arthritis (Fig. 1, p. 216).

A provisional diagnosis of rheumatoid arthritis was made. Rest was advised, the right ankle was strapped, and plaster-of-Paris splints were made for the wrists. The alternative diagnosis was gouty arthritis. As a diagnostic test, and because other drugs had been ineffective, it was decided 
to try treatment along the lines recommended by Bauer and Klemperer (1944) for cases of gout: 20 gr. each of sodium salicylate and sodium bicarbonate were advised thrice daily in an endeavour to lower the blood uric acid, and it was suggested that colchicine should be tried if an exacerbation of pain occurred.

The patient was seen again five weeks later. He stated that symptoms had continued in spite of rest and sodium salicylate and had steadily increased until three days previously, when pain became severe and he felt hot and tired. Marked swellings were noted by the patient in groins and axillae. On the day before admission to hospital he had begun taking colchicum and mercury pills (B.P.C.) prescribed by his doctor thrice daily, with, he thought, some improvement. Since the patient, however, was still obviously ill and in pain he was admitted to hospital.

On admission the joint findings noted when the patient was first seen were more marked, particularly in the left thumb and forefinger. The left ankle was also swollen and painful. In both groins and axillae there were visible and easily palpable swellings, most marked in right groin and left axilla. The glands were discrete, firm but not hard, and slightly tender. Examination of all other systems was negative.

Temperature was $98.2^{\circ} \mathrm{F}$; pulse 80 ; respiration 20 ; haemoglobin 95 per cent.; leucocytes 8,400 per 100 c.mm. of blood; differential count showed no abnormality; urine contained no abnormal constituents; blood sedimentation rate was $52 \mathrm{~mm}$. in one hour (Westergren); plasma uric acid was $4.4 \mathrm{mg}$. per $100 \mathrm{c.cm}$. of blood.

As some subjective improvement had resulted from the colchicum and mercury pills prescribed by the patient's doctor it was decided to continue with colchicine until symptoms of toxicity appeared, as recommended by Bauer and Klemperer (1944). Crystalline colchicine (0.5 mg.) was prescribed at two-hourly intervals throughout the day for six doses. Pain in the joints decreased, and this was accompanied by an improvement in the patient's general condition. Blood sedimentation rate fell to $12 \mathrm{~mm}$. in one hour. At 9 p.m. on the third day in hospital, after a total of $6 \mathrm{mg}$. colchicine had been administered, the patient complained abruptly of nausea and colicky abdominal pain. Treatment with colchicine was immediately stopped. These symptoms were followed by repeated vomiting and diarrhoea, which continued throughout the night and were unrelieved by morphia. On the following morning a moderate degree of shock was present. Vomiting and diarrhoea continued until the afternoon of the fourth day. Intravenous fluids were administered, and the patient's condition improved, but in the evening vomiting returned. Temperature was now $101^{\circ} \mathrm{F}$; pulse 120; respiration 30 . During the night the patient became comatose and incontinent. At this stage the urine contained no albumin or urobilinogen, and the blood urea nitrogen was $47 \mathrm{mg}$. per $100 \mathrm{c} . \mathrm{cm}$. of blood. The patient became more deeply comatose throughout the following day. Pulse and temperature continued to rise, and the patient died on the afternoon of the fifth day in hospital, forty-two hours after the onset of symptoms, three days after the prescription of colchicine in full doses in hospital, and five days after colchicine had been commenced as an out patient.

\section{Autopsy Findings}

\section{MACROSCOPIC}

The metacarpo-phalangeal joint of the left forefinger, when opened, showed thickening of the periarticular tissues and a roughened appearance of the articular surfaces. Glands removed from the right inguinal, left axillary, and supra-clavicular regions were moderately enlarged, but on section showed no naked-eye abnormality. The other positive findings were the presence in each pleural sac of about $200 \mathrm{c.cm}$. clear blood-stained fluid; at the apices of both lungs there were some emphysematous bullae, and on section the parenchyma was extremely congested, almost haemorrhagic, and very oedematous; the pericardial sac contained about $10 \mathrm{c.cm}$. of clear fluid; a few subepicardial petechial haemorrhages were present. No significant naked-eye abnormality was present in brain, meninges, mouth, pharynx, heart, aorta, stomach, large and small intestines, liver, gall bladder, bile ducts, spleen, or kidneys. 


\section{Microscopic}

Lymph Glands.-Sections of lymph glands taken from left supra-clavicular, axillary, and right inguinal regions showed a similar picture (Fig. 2). The germinal centres showed the greatest changes; these were common to every one examined. There was considerable variation in size of the centres, the largest being about five times as big as the smallest. Some were surrounded by a collar of lymphocytes two or three layers thick. A generalized necrosis was the most striking change. Nearly all of the constituent large lymphocytes were replaced by round particles of darkly staining granular matter- resembling pieces of degenerated pyknotic nuclei. A few recognizable but pale ghostly cells and histiocytes were present, but in view of their faint stain probably not viable. Some normal looking lymphocytes were distributed irregularly through the centre. The background consisted of an amorphous, eosinophilic material. The remainder of the gland showed no great changes, but the sinuses were fairly prominent, though empty. The vessels throughout the gland were prominent, dilated, and filled with red cells. No mitotic figures, normal or abnormal, were present.

Joint.-The articular surface of the base of the proximal phalanx of the left forefinger showed chronic arthritis. The articular cartilage was completely absent and replaced by a thick pannus of fibrous tissue. The synovia showed proliferated fingers, which were infiltrated with inflammatory round cells, and contained numerous dilated vessels. Below the articular surface was a zone of normal bone, and below this an area of bone necrosis. In this area there was a loss of cancellous structure which was replaced by a diffuse meshwork of faintly acidophile-staining material containing a large number of polymorphs and some lymphocytes. The picture suggested a small subacute abscess (Fig. 3).

Other Organs.-The section of the lung showed an acutely congested parenchyma. The alveolar capillaries were widely dilated, and engorged with blood. Many small haemorrhages had occurred, and here and there were alveoli within which were pigment containing macrophages. Some oedema was present in most of the alveoli.

The spleen was extremely congested, so much so that it was difficult to determine any pathological change. The malpighian corpuscles seemed to be reduced in diameter due to disappearance of the peripheral lymphocytes. No degenerative or necrotic changes could be seen in the lymphoid structure. Liver and kidney showed cloudy swelling only. Muscle showed no abnormality, in particular no evidence of nodular polymyositis.

\section{Discussion}

In toxic doses colchicine causes gastro-intestinal and renal irritation followed by progressive paralysis of the central nervous system. It is converted in the body to an oxidation product probably oxydicolchicine, which is excreted by bowel and kidney, and which in its excretion has an irritative action on excretory organs, possibly by causing capillary dilatation. This toxic action on the capillaries may be widespread and account for the profound shock in some cases. Terminal symptoms are due to the toxic action on the central nervous system.

The excretion of colchicine is slow, so there is a latent period of three or four hours between the toxic dose and symptoms. The main symptoms are nausea, vomiting, abdominal colic, diarrhoea, oliguria, shock, confusion, coma, and death.

Colchicine arrests mitosis at the metaphase, and has been shown to produce a regression in experimental tumours in laboratory animals. For this reason it has been used in the treatment of inoperable carcinoma. Brown and Seed (1945) 
describe two such cases treated with colchicine, which died from colchicine poisoning. These authors give the only detailed account of the autopsy findings in colchicine poisoning that we have found in the literature examined on this subject. They conclude that colchicine does not produce distinctive gross changes in the organs; the effects of the drug are visible only on microscopic examination, when arrest of mitosis at an early stage, usually the metaphase, occurs with the production of bizarre and abnormal nuclear configuration frequently leading to cell death. This effect is general and selective only in the same sense that those tissues which have the highest rate of cell division and metabolism are affected first; that is, bone marrow, tumours, skin, lymphoid structure, etc.

The present case is, therefore, typical of colchicine poisoning both in regard to clinical manifestations and autopsy findings. The massive necrosis of germinal centres of enlarged lymph glands is a manifestation of the action of colchicine on rapidly dividing cells. The significance of the lymphadenopathy is discussed later.

Few cases of colchicine poisoning have been described; fatalities have usually been the result either of large quantities of the wine being drunk in error, or of the prescribed dose being multiplied several times by the patient in an attempt to abort a severe attack of pain. Taylor (1934), in reviewing lethal cases, found it difficult to estimate the fatal dose of colchicine, but considered that one grain $(64.8 \mathrm{mg}$.) would be likely to produce fatal effects. Very much smaller doses have resulted in death. Details of these are given in the Table.

TABLE

\begin{tabular}{|c|c|c|}
\hline Case notes & $\begin{array}{l}\text { Dose of } \\
\text { colchicine }\end{array}$ & Quoted by \\
\hline $\begin{array}{l}\text { Male, aged } 47 \text {, took in } 1 \text { hour } 12 \text { capsules, each contain- } \\
\text { ing } 1 \mathrm{mg} \text {. of colchicine and } 20 \text { gr. of methyl salicylate. } \\
\text { Death occurred } 10 \text { days later. }\end{array}$ & $3 \mathrm{mg}$. & Taylor (1934) \\
\hline Death after drinking $15 \mathrm{c.cm}$. of tincture $\quad \ldots \quad \ldots$ & 4.5 mg.* & $\begin{array}{l}\text { Goodman and Gilman } \\
\text { (1943). }\end{array}$ \\
\hline $\begin{array}{l}\text { Male, aged } 39 \text {, given approximately } 7 \mathrm{mg} \text {. of colchicine } \\
\text { in } 4 \text { days, died } 42 \text { hours after onset of symptoms. }\end{array}$ & $7 \mathrm{mg}$. & Present case (1947) \\
\hline Death on fourth day after drinking $3 \frac{1}{2}$ drachms of vinum & $11 \mathrm{mg}$. & Taylor (1934) \\
\hline $\begin{array}{l}\text { Female, aged } 65 \text {, with inoperable carcinoma of the right } \\
\text { breast, was given } 13 \mathrm{mg} \text {. of colchicine over a period } \\
\text { of four days. Three days of vomiting, diarrhoea, and } \\
\text { prostration followed, and death occurred on the } \\
\text { seventh day after the first dose of colchicine. }\end{array}$ & $13 \mathrm{mg}$. & Brown and Seed (1945) \\
\hline
\end{tabular}

*Goodman and Gilman give the equivalent dose of colchicine as being $6 \mathrm{mg}$.

In the present case the patient stated he had taken one colchicum and mercury pill (B.P.C.) three times a day for two days before commencing the crystalline colchicine in hospital, representing an additional $0.6 \mathrm{mg}$. of colchicine. Death, 
therefore, occurred after a total of approximately $7 \mathrm{mg}$. of colchicine had been given over a period of four days.

Bauer and Klemperer (1944) state that hypersensitivity to colchicine is unknown. This statement has been repeated recently by Bauer (1947) and by Fletcher (1947). It will be seen in the Table that five fatal cases including the present one have been reported following $13 \mathrm{mg}$. or less of colchicine, that is, after a quantity that may be prescribed for therapeutic purposes. It is difficult to explain these cases, and, in particular, the present case, as other than very rare examples of hypersensitivity to colchicine.

In this country colchicine is usually prescribed as the tincture in doses of 20 minims four-hourly. This is equivalent to a daily total of approximately $2 \mathrm{mg}$. of colchicine. Because of the satisfactory results usually obtained on this dosage, and on consideration of the five fatal cases listed above, the prescription of colchicine in the doses recommended by Bauer and Klemperer must necessarily give rise to considerable anxiety. Accordingly we are of the opinion that if the pure drug is to be used the total dose of crystalline colchicine for the first day should not exceed $3 \mathrm{mg}$. In view of the delay in excretion of the drug it is advisable that the total daily dose should be divided equally throughout the twenty-four hours. On the first day an initial dose of $1 \mathrm{mg}$. may be given, and thereafter half a milligramme four-hourly for four doses. On the second and successive days half a milligramme should be prescribed six-hourly. The drug must be withdrawn on the relief of symptoms, or on the first sign of toxicity. The importance of warning the patient not to exceed the prescribed dose is obvious.

Other interesting features of this case are, the finding of a subacute abscess in relation to a joint whose pathology was otherwise typical of rheumatoid arthritis, and the widespread incidence of lymphadenopathy. An unusual opportunity is presented of correlating an exceptional pathological finding with the radiological features (Figs. 1 and 3). The punched-out areas interpreted as being suggestive of gout were presumably due to abscesses. Lymphadenopathy is described as occurring in rheumatoid arthritis, but opinion varies as to its frequency. Enlarged lymph glands were found in 19 per cent. of cases of rheumatoid arthritis by Freund (1929), in 53 per cent. by Coates and Delicati (1931), and in 9 per cent. by Waterhouse (1907). These different figures may be explained by different interpretations of pathologically enlarged glands, or by varying thoroughness in examining cases for this feature (Talkov and others, 1942). The present case was exceptional in that the enlargement of the glands was of such a degree that in the groin they were easily visible. In the writers' experience glandular enlargement of the order present in this case is rare in rheumatoid arthritis. This unusual feature may be explained by the presence of the abscesses in the sub-articular bone of some joints, the significance of which is not clear. It would appear that local infection of undetermined bacteriology and unknown source played a part in the aetiology of the arthritis and probably accounted for the marked lymphadenopathy in this case. 


\section{Summary}

A fatality following colchicine therapy is described in a case of atypical arthritis of the rheumatoid type.

It is suggested that this is a rare example of hypersensitivity to colchicine. The toxic effects of this drug are discussed and suggestions are made about its dosage.

Other unusual features of the case, marked lymphadenopathy and sub-articular bone abscesses, are briefly discussed, and the pathological and radiological findings are correlated.

We gratefully acknowledge our indebtedness to Professors L. S. P. Davidson and A. M. Drennan for much helpful criticism and advice.

\section{RFFERENCES}

Bauer, W. (1947). Personal communication.

- and Klemperer, F. (1944). New Engl. J. Med., 231, 681

Brown, W. O., and Seed, L. (1945). Amer. J. clin. Path., 15, 189.

Coates, V., and Delicati, L. (1931). "Rheumatoid Arthritis and its Treatment." London. H. K. Lewis. Quoted by Talkov and others.

Fletcher, E. (1947). “ Medical Disorders of the Locomotor System." Edinburgh. E. and S. - Livingstone. 1st edit., p. 478.

Freund, E. (1929). “ Gelenkerkrankungen.” Berlin. Urban and Schwarzenberg. Quoted by Talkov and others.

Goodman, L., and Gilman, A. (1943). “The Pharmacological Basis of Therapeutics." New York. The Macmillan Company. 1st edit., p. 239.

Talkov, R. H., Bauer, W., and Short, C. L. (1942). New Engl. J. Med., 227, 395.

Taylor's "Principles and Practice of Medical Jurisprudence". Edited and revised by Smith, S., and Cook, W. G. H. (1934). London. J. and A. Churchill. 9th edit., p. 784.

Waterhouse, R. (1907). St. Bart's. Hosp. Rep., 43, 107.

(For Illustrations to this Article see pages 216 and 217) 